\title{
PANORAMA ATUAL DA COBERTURA ARBÓREA DA CIDADE DE SÃO PAULO
}

CURRENT PANORAMA OFARBOREAL COVERING AT SÃO PAULO CITY

\author{
Marcela Minatel locatelli ${ }^{1}$, Bruna Lara Arantes ${ }^{2}$, Jefferson Lordello Polizel³ \\ Demóstenes Ferreira da Silva Filho ${ }^{4}$, Maria de Assunção Ribeiro Franco 5 .
${ }^{1}$ Engenheira Florestal, Mestranda em Recursos Florestais na Escola Superior de Agricultura "Luiz de Queiroz" da Universidade de São Paulo, Piracicaba, SP. marcelalocatelli@usp.br
Bióloga, mestre em Ciências - Recursos Florestais na Escola Superior de Agricultura "Luiz de Queiroz" da Universidade de São Paulo, Piracicaba, SP. blarantes@usp.br
${ }^{3}$ Doutor em Geografia Física pela Universidade de São Paulo, Técnico em Informática do Laboratório de Métodos Quantitativos, ESALQ/USP. jlpolize@usp.br

${ }^{4}$ Engenheiro Agrônomo, Professor Doutor em Ciências Florestais na Escola Superior de Agricultura "Luiz de Queiroz" da Universidade de São Paulo, Piracicaba, SP. dfilho@usp.br

\author{
${ }^{5}$ Arquiteta, Professora Titular na Faculdade de Arquitetura e \\ Urbanismo da Universidade de São Paulo, São Paulo, SP. \\ mariafranco@usp.br
}

\begin{abstract}
RESUMO
Nas cidades, cada vez mais, espaços vegetados são substituídos por asfalto e construções, principalmente nas regiões centrais, acarretando diversos problemas na estrutura da cidade e na preservação da biodiversidade urbana. O presente estudo teve como objetivo quantificar a cobertura arbórea da cidade de São Paulo/SP, discutindo suas implicações na paisagem urbana. Foi quantificado a cobertura arbórea de um trecho amostral da cidade de São Paulo/SP, através de imagens de Satélite Wordview 2 e software QuantumGIS, gerando o Índice de Vegetação (TVI) por distrito. A partir do TVI foram obtidas a área e a porcentagem de vegetação de cada distrito no software Fragstats. Os mais arborizados são: Cachoeirinha, Tremembé, Mandaqui, Vila
\end{abstract}


Andrade, e Morumbi; e os menos são: Limão, Santa Cecília, Cambuci, Sé e Brás. Somente dois distritos apresentam uma porcentagem de vegetação ideal prevista pela literatura. A cobertura arbórea parece estar associada ao nível de renda da região, sendo que os bairros nobres apresentam, em geral, maior porcentagem vegetação. Foi apresentado um cenário ambiental para a área de estudo, visando o aumento da porcentagem de cobertura arbórea e a conexão dos espaços vegetados existentes.

Palavras-chave: Índice de vegetação; TVI; Uso e ocupação do solo; sistema de informação geográfica; floresta urbana.

\section{ABSTRACT}

Green areas in the cities are increasingly being replaced by asphalt and buildings, mainly in downtown regions, causing several problems to the structure of the city and to the preservation of the urban biodiversity. This study aims to quantify the tree covering in São Paulo City, SP, discussing its implications in the urban landscape. It was quantified the arboreal covering of a sample section of São Paulo City, SP, by using images of Worldview 2 satellite and Quantum GIS software, generating the Vegetation Index (TVI) per district. With the TVI, the area and the percentage of vegetation of each district were obtained with Fragstats software. The most wooded areas are Cachoeirinha, Tremembé, Mandaqui, Vila Andrade, and Morumbi; and the less: Limão, Santa Cecilia, Cambuci, Sé and Brás. Only two districts present an ideal percentage of vegetation recommended by specific literature. Arboreal covering seems to be linked to the income level of the region, having the wealthy neighborhoods, in general, a higher percentage of vegetation. An environmental scenario for the study area was presented, aiming to increase the percentage of arboreal covering and the connection to existing vegetation spaces.

Keywords: Vegetation Index; TVI; Land Use and Occupation; Geographic Information System; Urban Forest

\section{INTRODUÇÃO}

Historicamente o crescimento das cidades ocorre sem um manejo eficiente dos elementos que a compõe, levando a paisagem a alterar-se significativamente ao longo do tempo, modificando sua dinâmica funcional. Essas alterações acarretam diversos problemas no seu bom funcionamento, na preservação da biodiversidade urbana e na qualidade de vida da população. 
Na maioria das vezes os espaços vegetados são substituídos por asfalto e construções, principalmente nas regiões centrais, acarretando diversos problemas na estrutura da cidade, como impermeabilidade do solo, enchentes, superaquecimento da superfície, diminuição da qualidade de vida, entre outros (NOBRE et al. 2010)

Florestas urbanas oferecem diversos serviços ecossistêmicos, dentre eles podemos destacar a economia do consumo de energia elétrica pela regulação térmica, absorção de carbono, retenção de poluentes, redução de ruídos urbanos e redução do escoamento superficial de águas pluviais (MCPHERSON, 1992; NOWAK et al. 2014; BARÓ et. al. 2017; MAHER et al. 2013).

Além disso, são associadas ao bem estar psicológico (LI, CHEN E HE, 2015), à diminuição dos sintomas de depressão, ansiedade e estresse (BEYER, K. et al., 2014), além de proporcionarem oportunidades de recreação e coesão comunitária e cultural (COSTA, 2010).

Para amenizar os problemas urbanos, gestores devem repensar o planejamento das cidades, substituindo áreas não permeáveis por áreas arborizadas, que aumentam a infiltração de água no solo, regulam a temperatura e promovem maior qualidade de vida.

Dentro desse panorama, o presente estudo teve como objetivo quantificar a cobertura arbórea de um trecho amostral da cidade de São Paulo/SP, discutindo suas implicações na paisagem urbana.

\section{MATERIAL E MÉTODOS}

\section{1. ÁREA DE ESTUDO}

A cidade de São Paulo está localizada no estado de São Paulo/Brasil, com uma elevação de 802 metros, latitude de $23^{\circ} 37^{\prime}$ e longitude $46^{\circ} 39^{\prime}$ W. Possui $1.521 \mathrm{Km}^{2} \mathrm{de}$ extensão e concentra 11.253.503 habitantes (IBGE, 2010). O clima é classificado como subtropical (Cwa), com temperatura média anual de $19^{\circ} \mathrm{C}$, e precipitação média anual de 1207 mm (Köppen, 1948).

A área do município engloba as fitofisionomias da Mata Atlântica: Floresta Ombrófila Densa, Floresta Ombrófila Montana e a Mata Nebular; bem como campos naturais e formações de várzea. 
A área de interesse do presente trabalho corresponde a uma 'faixa de transepto' de $5 \times 20 \mathrm{Km}$ da cidade de São Paulo, objeto de estudo do Projeto de Pesquisa "Infraestrutura verde para a resiliência urbana às mudanças climáticas da cidade de São Paulo" financiado pela FAPESP ${ }^{1}$ (Fundação de Amparo à Pesquisa no Estado de São Paulo).

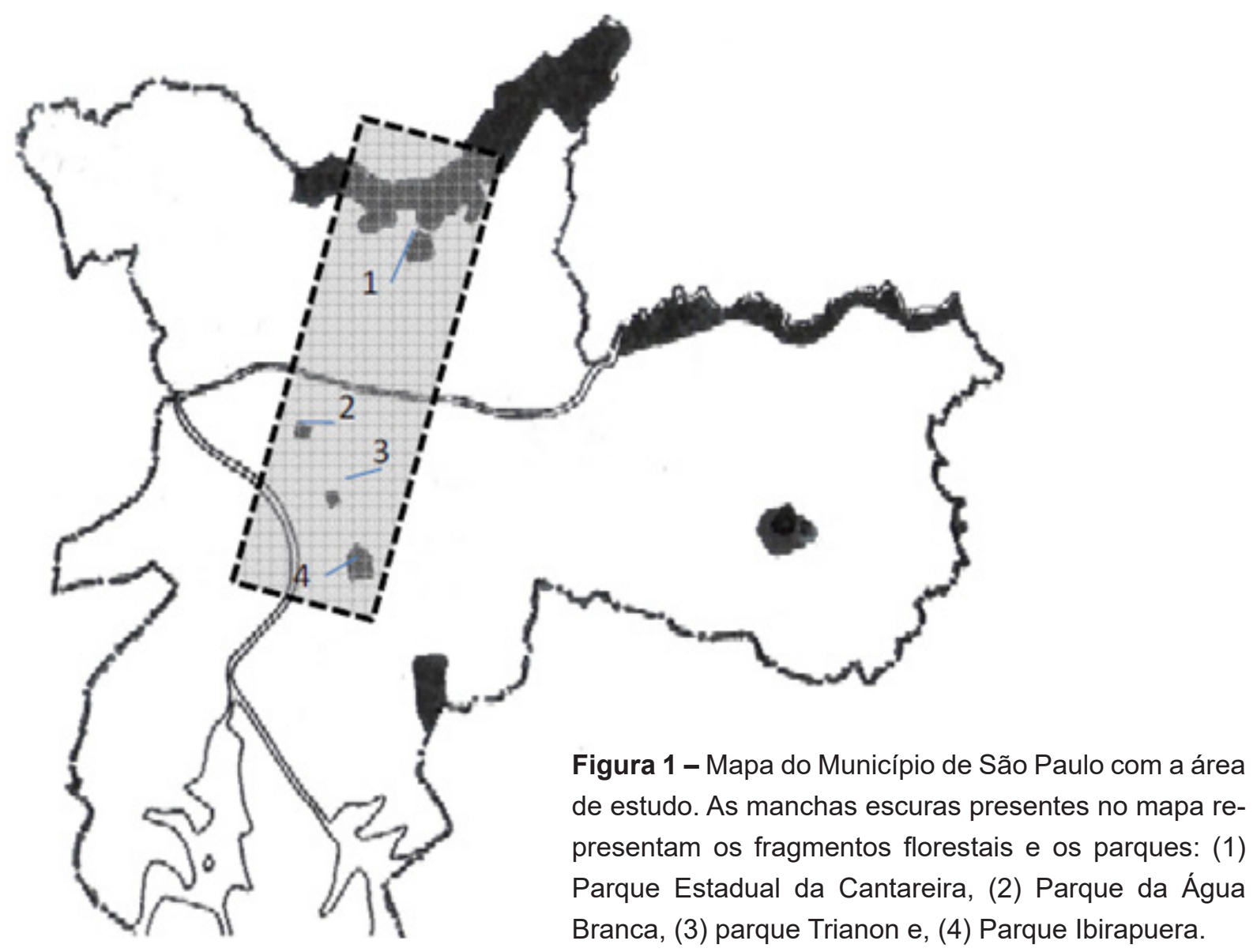

As análises foram desenvolvidas a partir de dados obtidos de imagens do Satélite Wordview 2 do ano de 2016 com resolução de dois metros, cedidas pela

Fundação DigitalGlobe, e processados em ambiente SIG (Sistema de Informação Geográfica). Para a determinação da área e porcentagem de vegetação da área de estudo, foi calculado o Índices de Vegetação (TVI) no software QuantumGIS, versão 2.18.4.

\footnotetext{
${ }^{1}$ Projeto em andamento e financiado pela FAPESP na modalidade Auxílio à Pesquisa - Programa de Pesquisa sobre Mudanças Climáticas Globais - Regular, cujo Processo é 15/10597-0.
} 
O TVI (Transformed Vegetation Index) é um índice de vegetação derivado de imagens multiespectrais, que utiliza as bandas do vermelho e do infravermelho próximo para destacar as áreas vegetadas de uma imagem (COSTA, 2010), e é obtido pela Fórmula:

$$
\mathrm{TVI}=\sqrt{100[(I R-R E D)]+[(I R+R E D)]}
$$

Onde: TVI é o índice de vegetação; IR = banda do infravermelho e; RED = banda do vermelho.

Os valores de TVI variam de 1 (mínimo de vegetação) a 100 (máximo de vegetação). O mapa de TVI foi gerado no software QuantumGIS, versão 2.18.4, onde foi também reclassificado em duas classes: a classe 1 (área não vegetada) compreende os valores de TVI entre 1 e 55; a classe 2 (cobertura arbórea) compreende os valores de TVI entre 55 e 100.

A classe 1, denominada de área não vegetada, compreende diversos tipos de uso do solo, como: áreas edificadas (casas, prédios, indústrias, etc.), asfalto, solo exposto, rios e lagos e vegetação rasteira. Já a classe 2, denominada de cobertura arbórea, corresponde às áreas de vegetação arbórea-arbustiva.

O mapa gerado foi analisado no software Fragstats 4.2 para a obtenção da área e da porcentagem de cobertura arbórea da área de estudo. Posteriormente, o mapa foi recortado de acordo com os distritos de São Paulo componentes da área de estudo. Cada distrito foi analisado no software Fragstats 4.2.

\section{RESULTADOS E DISCUSSÃO}

\section{1. ÍNDICE DE VEGETAÇÃO (TVI)}

Os resultados obtidos para o TVI são apresentados na Figura 2, em que as áreas mais claras correspondem às áreas vegetadas, enquanto que as áreas escuras correspondem às áreas com ausência de vegetação. 
A Figura 3 apresenta os resultados da reclassificação da imagem, em que o valor 1 corresponde às áreas não vegetadas, e o valor 2, às áreas compostas por vegetação arbórea-arbustiva.

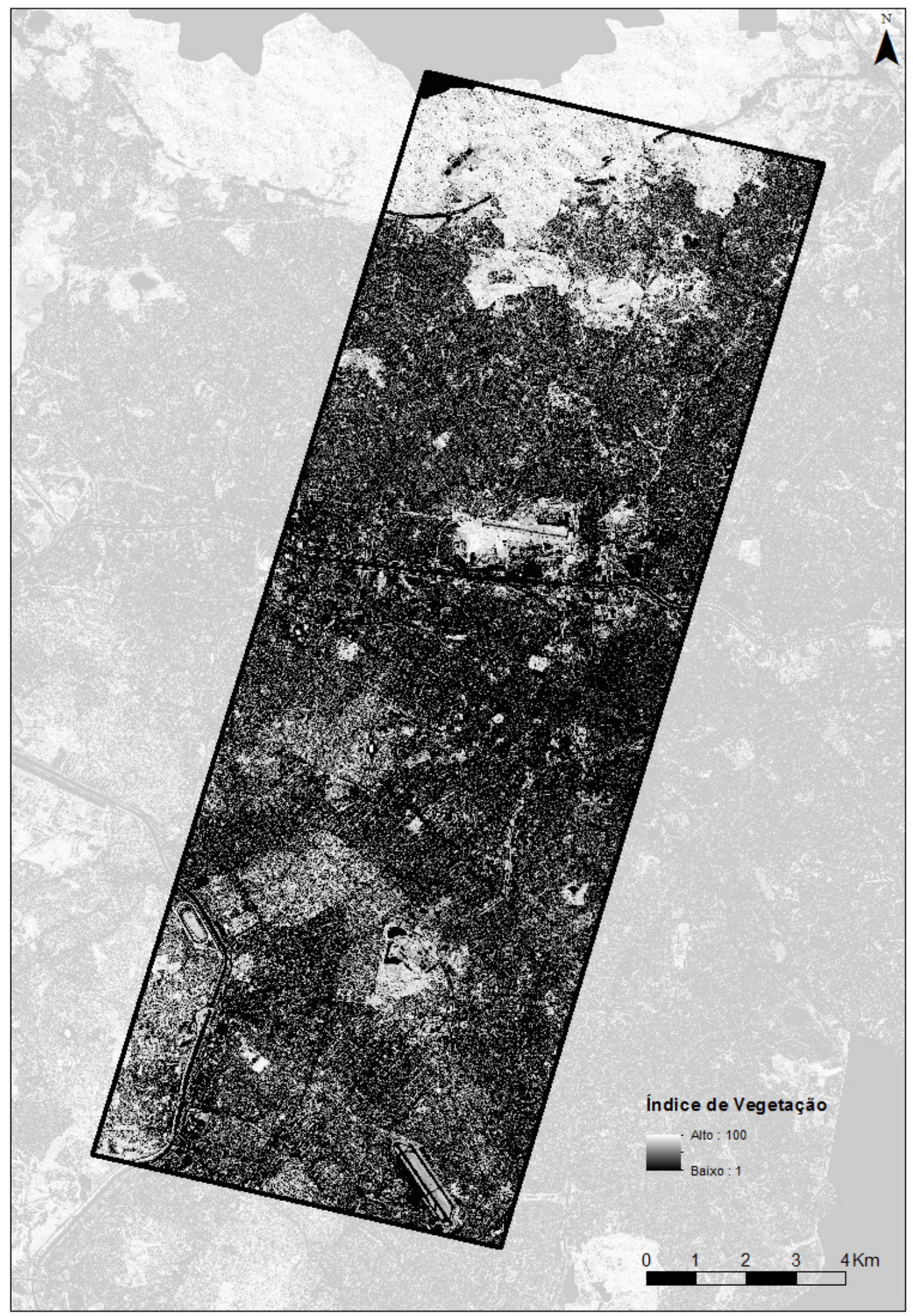

Figura 2 - Índice de vegetação (TVI) da área de estudo. 


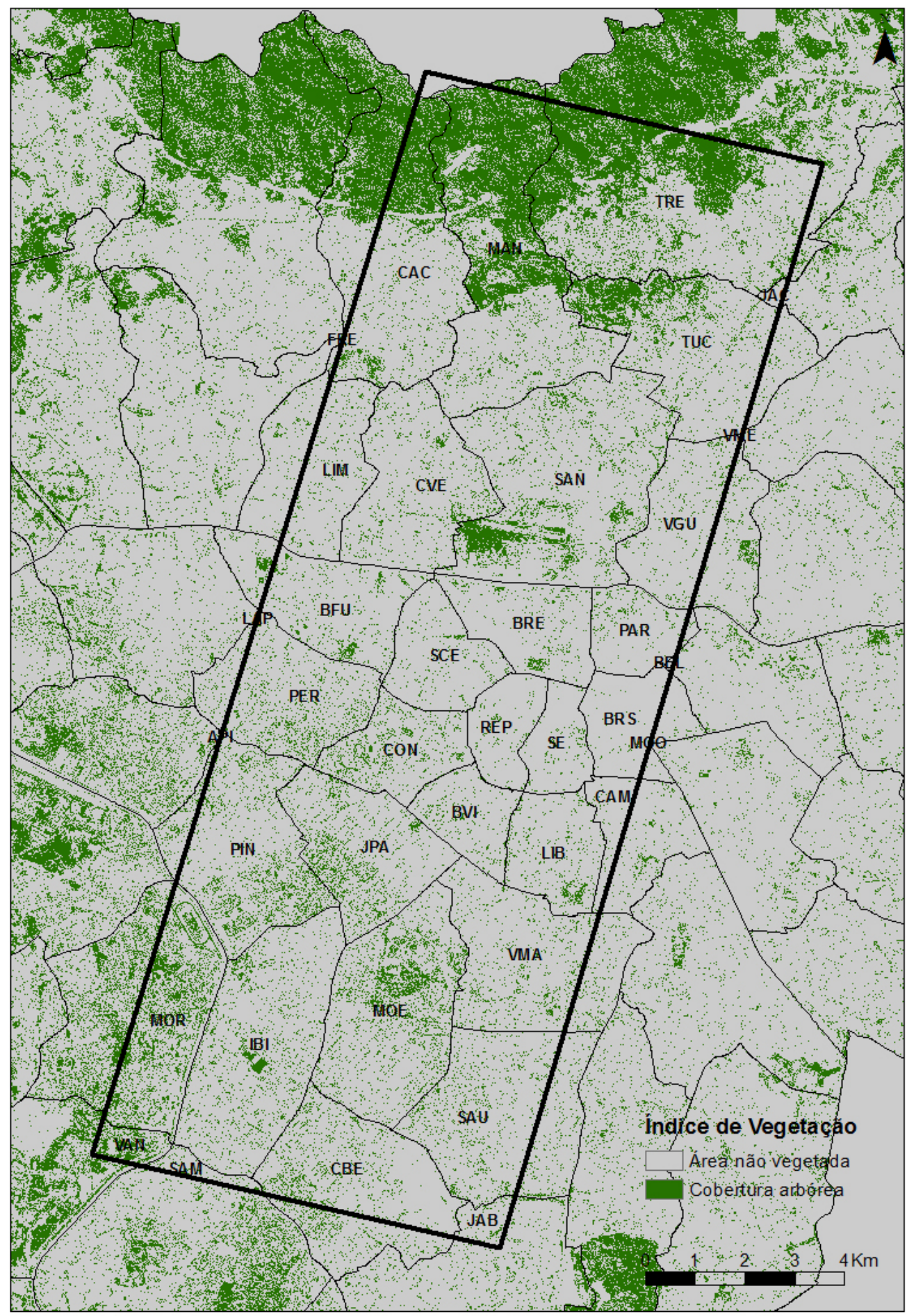

Figura 3 - Índice de vegetação (TVI) reclassificado em duas classes da área de estudo, em que o valor 1 corresponde à áreas não vegetadas; e o valor 2 corresponde à áreas compostas por vegetação arbórea-arbustiva.

MAN: Mandaqui, VAN: Vila Andrade, TRE: Tremembé, MOR: Morumbi, CAC: Cachoeirinha, TUC: Tucuruvi, MOE: Moema, PIN: Pinheiros, SAN: Santana, JPA: Jardim Paulista, CON: Consolação, PER: Perdizes, CBE: Campo Belo, JAB: Jabaquara, IBI: Itaim Bibi, SAM: Santo Amaro, SAL: Saúde, BFU: Barra Funda, LIB: Liberdade, VMA: Vila Mariana, CVE: Casa Verde, BRE: Bom Retiro, BVI: Bela Vista, PAR: Pari, JAC: Jaçanã, LIM: Limão, VME: Vila Medeiros, SCE: Santa Cecília, VGU: Vila Guilherme, SE: Sé, CAM: Cambuci, REP: República, BRS: Brás, API: Alto de Pinheiros, LAP: Lapa, FRE: Freguesia do Ó, BEL: Belém, MOO: Mooca. 
Por meio da aplicação do TVI foi possível destacar as áreas vegetadas, em contraposição àquelas áreas com ausência de vegetação. Quando reclassificado, o mapa de TVI aponta com clareza as áreas compostas por vegetação arbórea-arbustiva, mostrando a utilidade do índice para quantificação da cobertura arbórea urbana em macro-escala.

Podemos verificar que as áreas com máximo índice de vegetação correspondem a fragmentos de vegetação remanescentes e a parques importantes da cidade de São Paulo, como o Parque Estadual da Cantareira, o Parque Ibirapuera, o Parque da Água Branca e o Parque Trianon.

Nota-se que apesar de área de estudo apresentar uma porcentagem média de 21,02\% e 3.626,65 hectares de cobertura arbórea, a vegetação encontra-se dispersa de forma bastante heterogênea pelo território, sendo alguns distritos bem arborizados, enquanto outros são muito carentes em vegetação, conforme descrito a seguir.

A fim de ranquear as regiões, apresentamos os distritos de São Paulo presentes na área de estudo por ordem decrescente de vegetação, em hectares e porcentagem do uso do solo (Tabela 1).

Tabela 1 - Área (hectare) e Vegetação (porcentagem) em cada distrito de São Paulo/ SP da área de estudo, em destaque os mais e menos arborizados, com asterisco aqueles com quantidade amostral não considerada.

\begin{tabular}{ccc}
\hline Distrito & Área Vegetada (ha) & Vegetação (\%) \\
\hline Vila Andrade & 44,76 & 50,81 \\
Mandaqui & 636,17 & 48,96 \\
Tremembé & 657,84 & 45,18 \\
Morumbi & 215,51 & 36,68 \\
Cachoeirinha & 242,84 & 29,96 \\
Tucuruvi & 202,06 & 25,04 \\
Moema & 206,24 & 22,72 \\
Pinheiros & 143,32 & 19,21 \\
Santana & 245,33 & 18,74 \\
Jardim Paulista & 109,86 & 17,76 \\
Consolação & 66,17 & 17,34 \\
Perdizes & 82,82 & 15,63 \\
Campo Belo & 95,67 & 15,13
\end{tabular}




\begin{tabular}{ccc} 
Jabaquara & 10,14 & 13,19 \\
Itaim Bibi & 128,27 & 12,79 \\
Santo Amaro & 8,65 & 12,54 \\
Barra Funda & 54,49 & 11,52 \\
Saúde & 77,02 & 11,49 \\
Liberdade & 39,76 & 10,89 \\
Vila Mariana & 69,07 & 10,40 \\
Casa Verde & 70,32 & 9,76 \\
Pari & 24,07 & 9,30 \\
Bom Retiro & 38,92 & 9,25 \\
Bela Vista & 24,62 & 9,06 \\
Jaçanã & 1,36 & 8,10 \\
Limão & 30,14 & 7,97 \\
Santa Cecilia & 26,69 & 7,10 \\
Vila Guilherme & 31,23 & 7,02 \\
Sé & 15,33 & 6,99 \\
Cambuci & 7,25 & 6,17 \\
República & 13,21 & 5,51 \\
Brás & 7,13 & 2,72 \\
Alto De Pinheiros* & 0,01 & 26,09 \\
Lapa* & 0,20 & 13,29 \\
Vila Medeiros & 6,64 \\
Freguesia Do Ó* & 0,03 & 2,93 \\
Belém* & 0,01 & 0,73 \\
Mooca* & 0,03 & 0,00 \\
\hline & 0,00 & \\
\hline & & 6,03 \\
\hline
\end{tabular}

Os resultados de área e porcentagem de vegetação obtidos para os distritos: Belém, Lapa, Alto de Pinheiros, Mooca e Freguesia do Ó foram extremamente baixos, uma vez que sua área inserida na 'faixa de transepto' é muito pequena (Figura 3). Dessa forma, os resultados obtidos para os distritos mencionados não foram considerados nas discussões.

A área de estudo apresenta uma porcentagem média de vegetação de $12,50 \%$, que segundo estudos está abaixo do ideal para mitigação de ilhas de calor, qual seria de 30\% (LOMBARDO, 1985), e abaixo do ideal para uma cidade metropolitana, que seria de $40 \%$ (AMERICAN FORESTS, 2008).

Quando avaliados os resultados para cada distrito, nota-se grande disparidade. Considerando o IDHM (Índice de desenvolvimento humano municipal), aqueles com maiores porcentagens de vegetação correspondem às regiões com maiores índices de 
renda: Cachoeirinha e Tremembé com 0.88, Mandaqui 0.90, 0.88, Vila Andrade e Morumbi com 1.00 (Atlas Brasil, 2010), que abrangem ainda, grandes parques e fragmentos de vegetação remanescentes (Figura 4).

Em contrapartida, as regiões com menores porcentagens de vegetação apresentam, em média, um menor IDHM: Limão 0.74, Santa Cecília 0.77, Cambuci 0.83, Sé 0.83, Brás 0.82 (Atlas Brasil, 2010), estes distritos correspondem à regiões centrais da cidade, de caráter comercial.
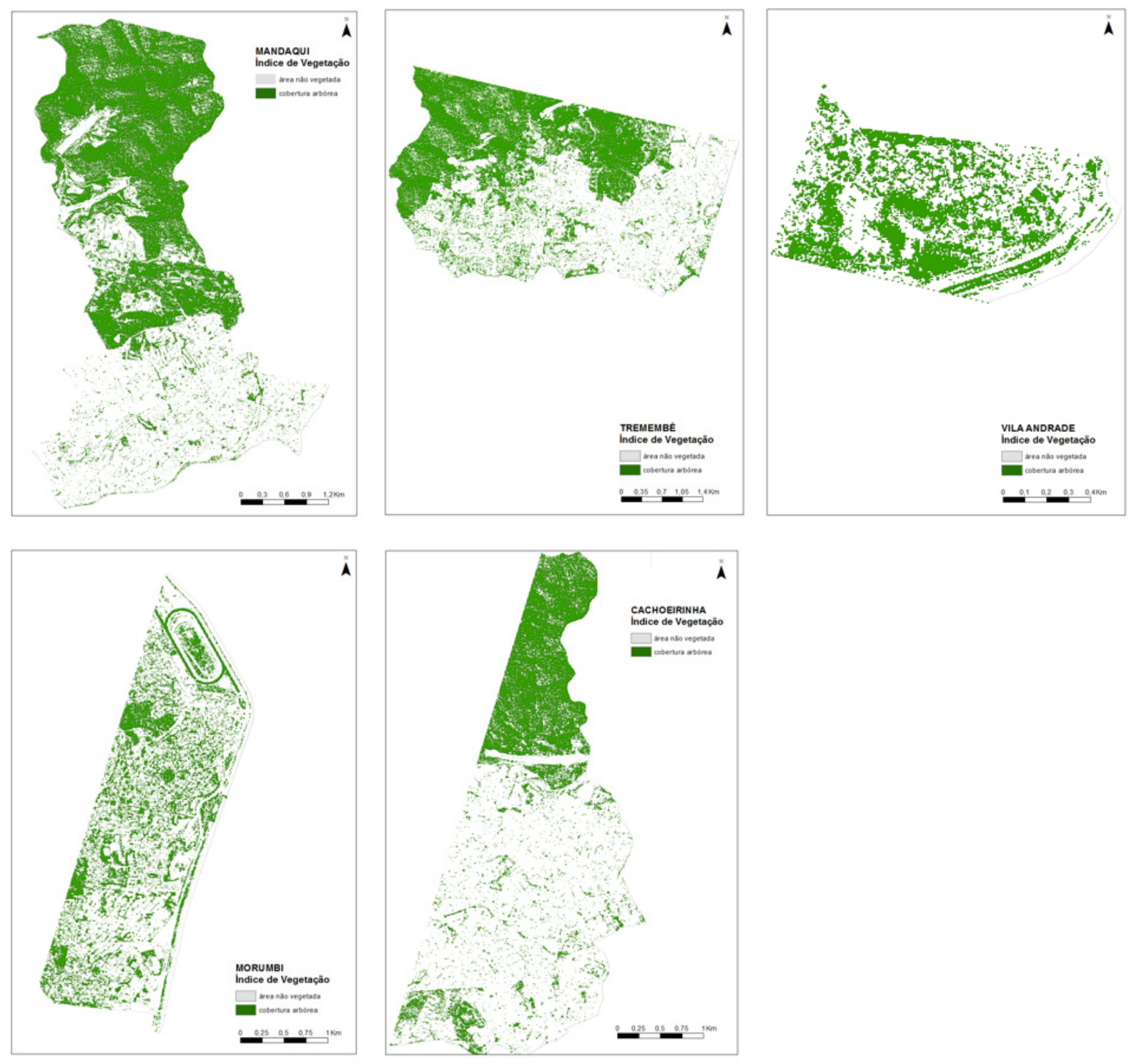

Figura 4 - Mapas dos distritos com os maiores índices de vegetação da área de estudo: Mandaqui, Tremembé, Vila Andrade, Morumbi e Cachoeirinha, em que a cor verde representa a área de vegetação arbórea-arbustiva, e a cor branca representa a área não vegetada. Fonte: Elaborado pelos autores. 

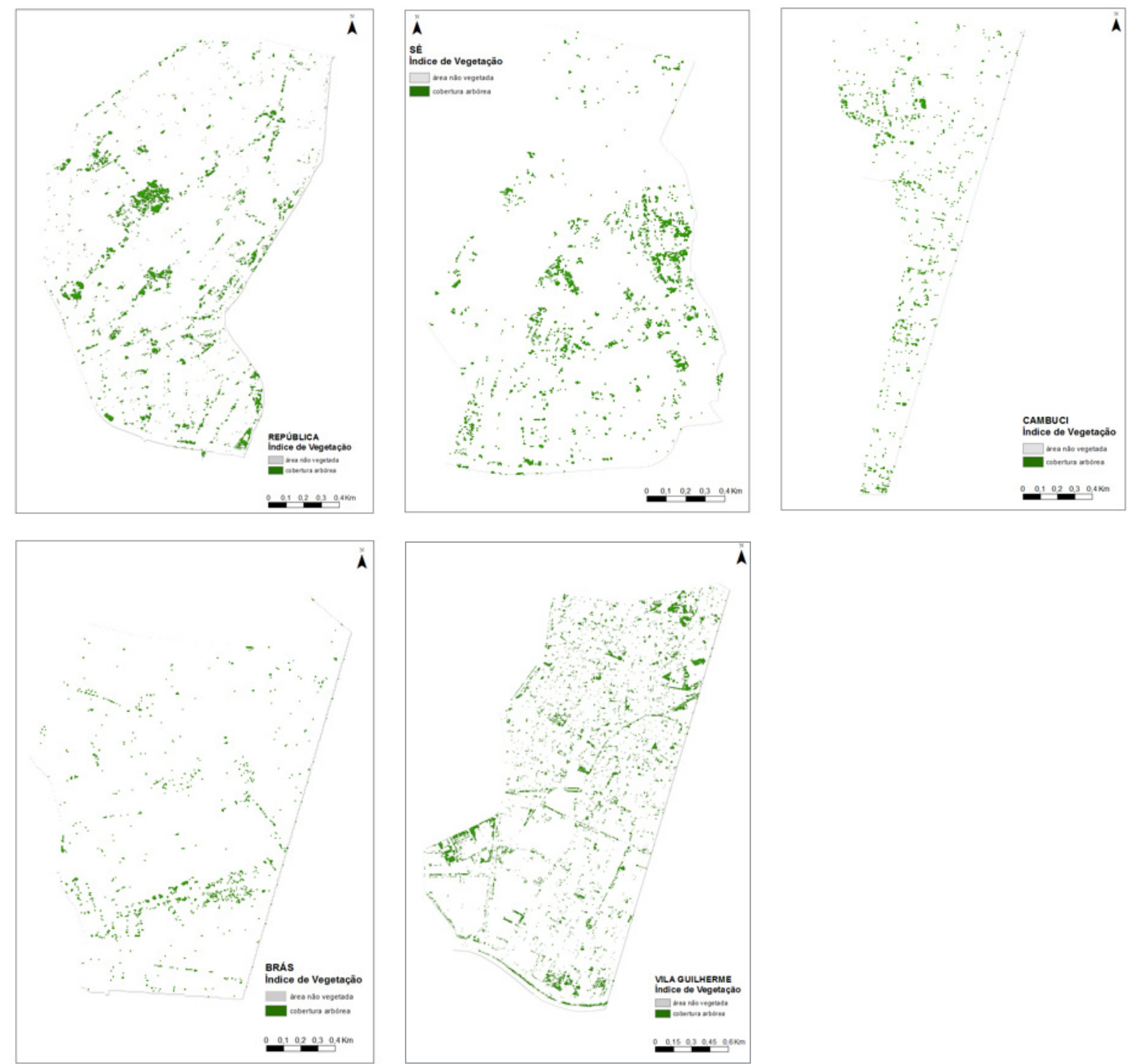

Figura 5 - Mapas dos distritos com os menores índices de vegetação da área de estudo: Limão, Santa Cecília, Cambuci, Sé e Brás, em que a cor verde representa a área de vegetação arbórea-arbustiva, e a cor branca representa a área não vegetada. Fonte: Elaborado pelos autores.

Nota-se que os mapas de índice de vegetação dos distritos representados na Figura 4. e na Figura 5. são bem discrepantes. Os distritos Mandaqui, Tremembé, e Cachoeirinha apresentam porcentagem de vegetação elevada, devido principalmente a presença do Parque Estadual da Cantareira.

Já os distritos Morumbi e Vila Andrade apresentam arborização urbana abundante, assim como grande número de parques e fragmentos florestais remanescentes. Esses fragmentos encontram-se ameaçados pela especulação imobiliária e 
pelo crescimento elevado de bairros como o Vila Andrade, que teve um aumento populacional de $72 \%$ na última década (O ESTADO DE S. PAULO, 2014). Essas regiões possuem elevada disparidade socioeconômica, pois nelas estão localizados diversos bairros nobres conjuntamente com a maior favela da cidade de São Paulo, Paraisópolis.

Em contraste, os distritos República, Vila Guilherme, Cambuci, Sé e Brás compreendem grandes centros comerciais e industriais da cidade de São Paulo. Essas regiões são caracterizadas pela elevada densidade demográfica, elevado nível de impermeabilização do solo e arborização urbana escassa. Tais características conferem a esses espaços diversos problemas, como ilhas de calor, alagamentos e elevados níveis de poluição (COSTA, 2010).

Em regiões metropolitanas do leste do rio Mississipi, nos Estados Unidos, pesquisas recomendam as seguintes taxas de cobertura arbórea: $50 \%$ para áreas residenciais de subúrbios; $25 \%$ para áreas residenciais urbanas; $10 \%$ a $15 \%$ para áreas urbanas centrais (AMERICAN FORESTS, 2008).

A partir dessas pesquisas, faz-se uma abordagem comparativa dos dados encontrados aqui com o índice ideal apontado pelos autores (Tabela 2).

Sabemos que a cidade de São Paulo é diferente das cidades americanas em muitos aspectos, entretanto, adaptamos as classes das cidades americanas apresentadas anteriormente para a cidade de São Paulo. As porcentagens de vegetação mencionadas não são absolutas, e sim um ideal teórico para embasar as discussões acerca da vegetação da cidade. Assim, as áreas periféricas próximas ao Parque Estadual da Cantareira foram comparadas às áreas residenciais e subúrbios (porcentagem de vegetação ideal de $50 \%$ ); os bairros residenciais, às áreas residenciais urbanas (porcentagem de vegetação ideal de $25 \%$ ); e os centros comerciais às áreas urbanas centrais (porcentagem de vegetação ideal de 15\%). 
Tabela 2 - Comparação da arborização encontrada no município de São Paulo com os índices estabelecidos pelo American Forests (2008), apresentando a diferença entre o observado e o esperado.

\begin{tabular}{|c|c|c|c|}
\hline Distrito & Vegetação (\%) & American Forests, 2008 (\%) & Diferença (\%) \\
\hline Vila Andrade & 50,81 & 25 & 0 \\
\hline Morumbi & 36,68 & 25 & 0 \\
\hline Perdizes & 15,63 & 15 & 0 \\
\hline Consolação & 17,34 & 15 & 0 \\
\hline Mandaqui & 48,96 & 50 & 1,04 \\
\hline Moema & 22,72 & 25 & 2,28 \\
\hline Barra Funda & 11,52 & 15 & 3,48 \\
\hline Liberdade & 10,89 & 15 & 4,11 \\
\hline Tremembé & 45,18 & 50 & 4,82 \\
\hline Pari & 9,30 & 15 & 5,70 \\
\hline Bom Retiro & 9,25 & 15 & 5,75 \\
\hline Pinheiros & 19,21 & 25 & 5,79 \\
\hline Bela Vista & 9,06 & 15 & 5,94 \\
\hline Santana & 18,74 & 25 & 6,26 \\
\hline Jardim Paulista & 17,76 & 25 & 7,24 \\
\hline Santa Cecília & 7,10 & 15 & 7,90 \\
\hline Sé & 6,99 & 15 & 8,01 \\
\hline Cambuci & 6,17 & 15 & 8,83 \\
\hline República & 5,51 & 15 & 9,49 \\
\hline Campo Belo & 15,13 & 25 & 9,87 \\
\hline Jabaquara & 13,19 & 25 & 11,81 \\
\hline Itaim Bibi & 12,79 & 25 & 12,21 \\
\hline Brás & 2,72 & 15 & 12,28 \\
\hline Santo Amaro & 12,54 & 25 & 12,46 \\
\hline Saúde & 11,49 & 25 & 13,51 \\
\hline Vila Mariana & 10,40 & 25 & 14,60 \\
\hline Casa Verde & 9,76 & 25 & 15,24 \\
\hline Jaçanã & 8,10 & 25 & 16,90 \\
\hline Limão & 7,97 & 25 & 17,03 \\
\hline Vila Guilherme & 7,02 & 25 & 17,98 \\
\hline Cachoeirinha & 29,96 & 50 & 20,04 \\
\hline Tucuruvi & 25,04 & 50 & 24,96 \\
\hline
\end{tabular}

Podemos observar que somente dois distritos (Vila Andrade e Morumbi) possuem valores acima do valor ideal sugerido. Estes bairros são considerados de alta renda, mas possuem uma realidade muito complexa. 
Vila Andrade e Morumbi são bairros muito próximos, urbanizados a partir do loteamento da antiga Fazenda Morumby, nos anos 50, e cresceram de forma desordenada, o que gerou grande desigualdade social na região, e o consequente surgimento da favela de Paraisópolis na década de 70 (O ESTADO DE S. PAULO, 2014).

Apresentamos a seguir uma imagem aérea do distrito Vila Andrade, que compreende bairros nobres como o Parque Bairro Morumbi e o Jardim Parque Morumbi (à esquerda), bem como a favela Paraisópolis (à direita).

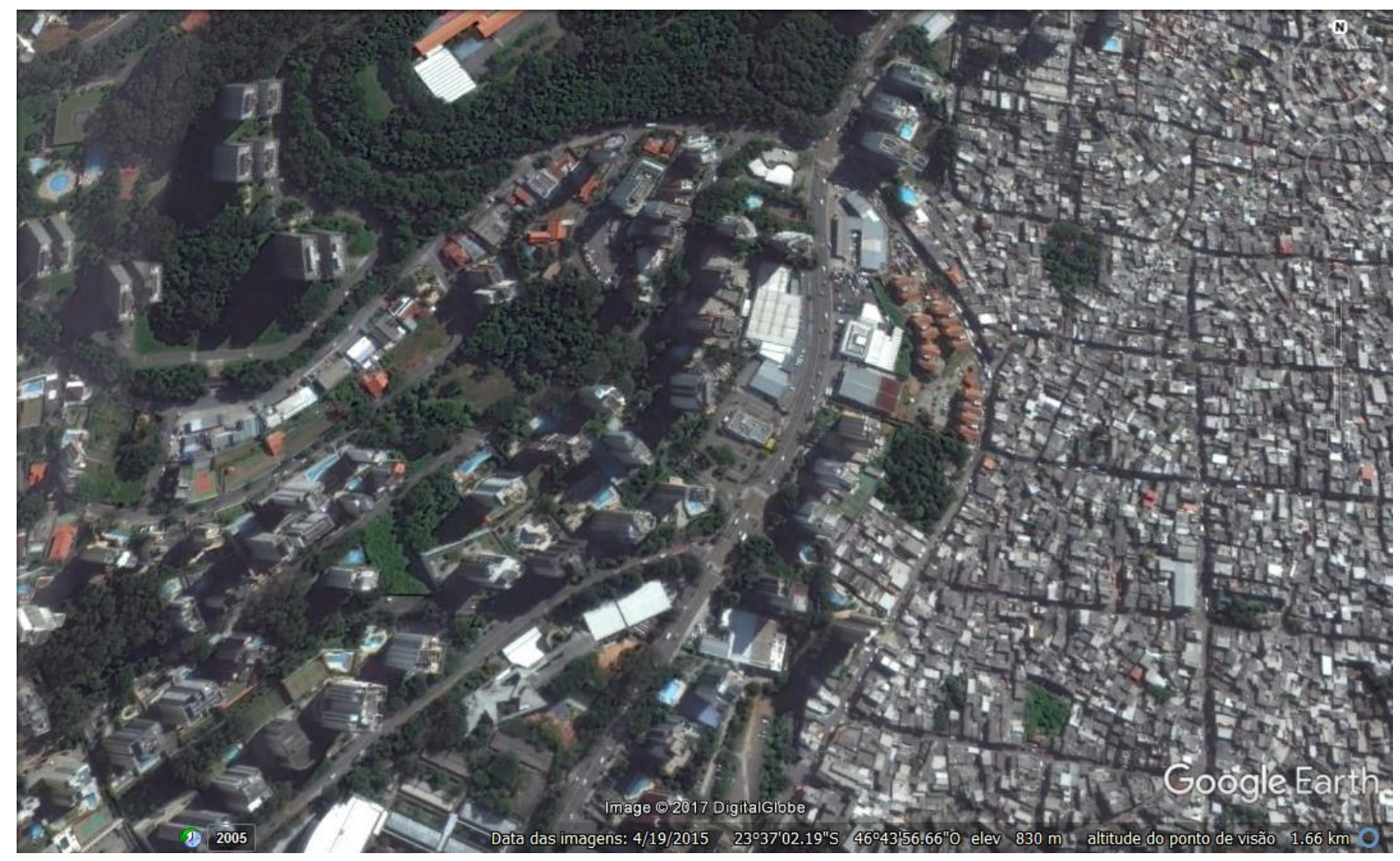

Figura 6 - Imagem aérea do distrito Vila Andrade. Fonte: Google Earth

Podemos observar na imagem a grande quantidade de áreas verdes nos bairros nobres do distrito, em contraposição à porcentagem baixíssima de vegetação na favela Paraisópolis.

Os distritos Perdizes e Consolação apresentam valores de porcentagem de vegetação próximos aos valores sugeridos. Entretanto, acreditamos que a porcentagem de vegetação desses locais ainda é baixa, tendo em vista os problemas ambientais, e a quantidade de pessoas e serviços que essas regiões concentram. 
Apesar de os distritos Mandaqui, Tremembé e Cachoeirinha apresentarem as maiores porcentagens de vegetação da área de estudo, esses não possuem os valores de porcentagem de vegetação ideal sugerido. Nota-se que a vegetação presente nesses locais é concentrada no Parque Estadual da Cantareira, sendo esta menos abundante no tecido urbano.

Duarte e Serra, 2003 recomendam que os espaços vegetados sejam distribuídos homogeneamente pelo espaço construído, considerando o efeito extremamente localizado da vegetação sobre as condições climáticas locais (Duarte e Serra, 2003). Segundo o mesmo autor, a partir de certo ponto, o tamanho de um único parque faz pouca diferença nas condições climáticas além de seus limites. Porém, a divisão da área verde em um maior número de pequenos parques, espalhados por toda a cidade, estende os benefícios a uma área maior e a um maior número de pessoas.

Vale ressaltar que não estamos propondo a fragmentação do Parque Estadual da Cantareira. Estes deve ter sua morfologia mantida, pois é fundamental para a manutenção da biodiversidade urbana, e por fornecer todos os benefícios já mencionados. A distribuição equitativa da vegetação refere-se às novas áreas a serem arborizadas. Dessa forma, os espaços vegetados poderiam ser pensados como um sistema integrado, onde a arborização urbana poderia manter a conectividade entre o Parque Estadual da Cantareira e os espaços vegetados urbanos, de acordo com as ideias de Forman e Godron (1986).

Cabe salientar que os valores apresentados na Tabela 2. não são absolutos, e sim uma referência geral para a cobertura arbórea de grandes cidades. Segundo Leff (2016), não existe um nível de cobertura arbórea considerado "ótimo" em todos os locais. Cada comunidade deve adotar seus próprios objetivos, dependendo de uma série de considerações, incluindo clima, geografia, preocupações ambientais específicas, preferências locais, serviços ecossistêmicos desejados, padrões de uso e ocupação do solo, recursos e outros fatores. De acordo com o mesmo autor, mais importante que atingir o nível "ótimo" de cobertura arbórea, é encontrar a melhor forma de otimizar a cobertura do dossel - pesando os benefícios desejados em relação aos custos associados.

Tendo em vista o déficit de vegetação da cidade de São Paulo, bem como a necessidade de conexão dos espaços vegetados existentes, apresentamos um cenário ambiental, proposto anteriormente por Franco no Relatório Científico de Progresso 
(R-1 FAPESP/Anual) do Projeto de Pesquisa "Infraestrutura verde para a resiliência urbana às mudanças climáticas da cidade de São Paulo"1. Este cenário visa a criação de dois corredores verdes, denominados de Trilha Norte-Sul 1 e Trilha Norte Sul 2 (Figura 7.).

Ambos os corredores percorrem a área de estudo no sentido Norte-Sul ao longo de grandes avenidas da cidade, localizadas, em sua maioria, nos fundos de vale, sobre rios canalizados ou ocultos. Dessa forma, a vegetação componente desses corredores pode ter a função de vegetação ciliar, além das demais funções anteriormente apresentadas.

Além da implantação da infraestrutura verde nas vias onde os corredores serão estruturados, as Trilhas Norte-Sul 1 e 2 contemplam a criação de zonas de amortecimento de 500 metros em ambos os lados das referidas vias, que serão densamente arborizadas. Para o presente estudo consideramos uma porcentagem de cobertura arbórea de $60 \%$ para as trilhas, porcentagem semelhante à dos bairros densamente arborizados de São Paulo.

No cenário ambiental proposto, a área total de vegetação da área de estudo aumentaria de 3.626,65 hectares para aproximadamente $5.708,29$ hectares, enquanto a porcentagem média de cobertura arbórea aumentaria de $21,02 \%$ para $27,72 \%$.

Além de aumentar significativamente a porcentagem média de cobertura arbórea da área de estudo, vale ressaltar que os corredores percorrem regiões muito carentes em vegetação, como os distritos: Santana, Casa Verde, Limão, Barra Funda, Perdizes, Itaim-Bibi, Vila Guilherme, Bom Retiro, Sé, República, Liberdade, Bela Vista, Vila Mariana, Saúde e Campo Belo. Dessa forma, com a consolidação do cenário proposto, a porcentagem de cobertura arbórea desses distritos aumentaria expressivamente. Espera-se também uma alteração no microclima desses locais, com amenização das ilhas-de-calor; melhor qualidade do ar; maior permeabilidade do solo e consequente redução dos riscos de alagamento, dentre outros benefícios fornecidos pelos espaços vegetados. 


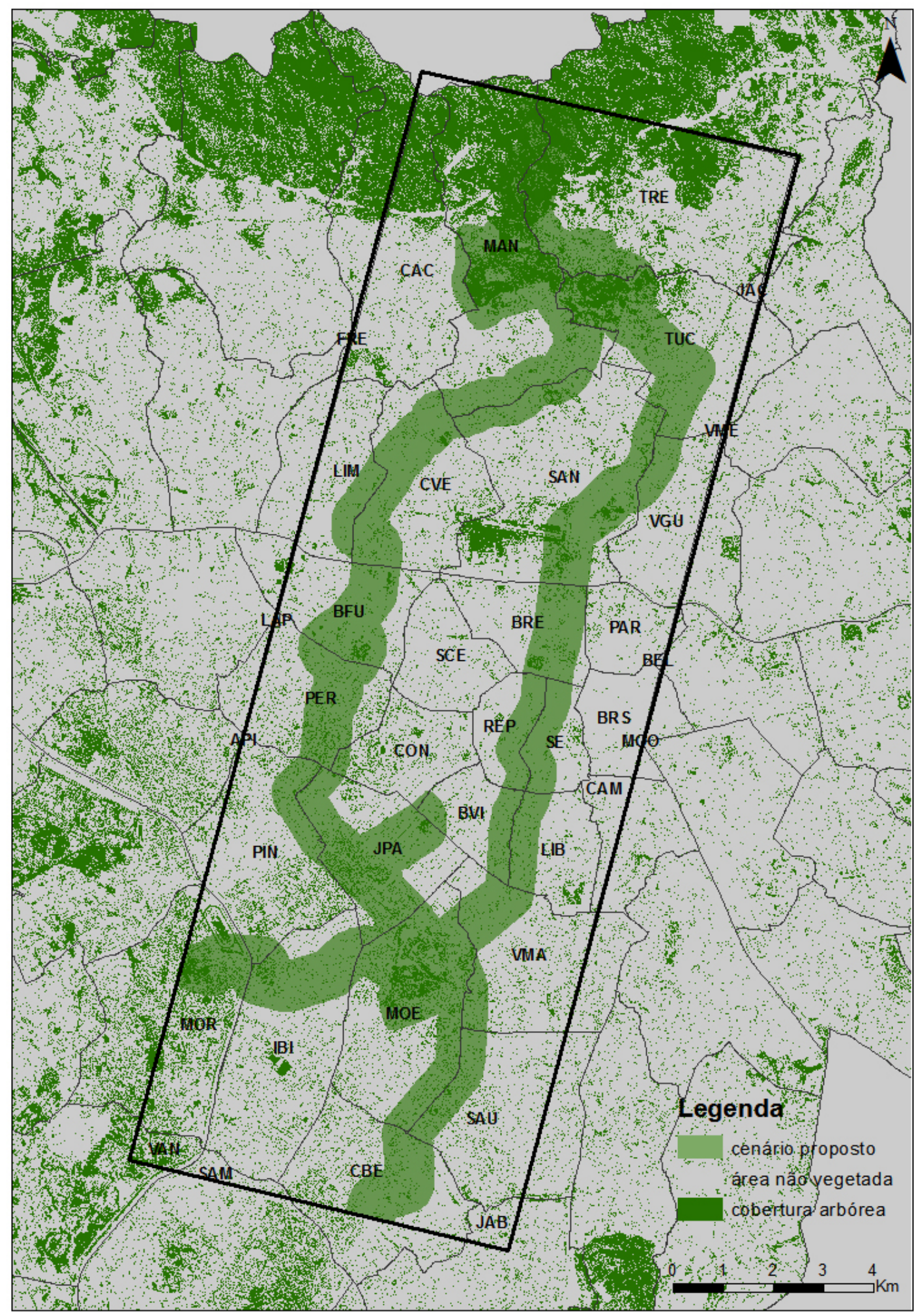

Figura 7 - Cenário ambiental proposto (Trilha Norte-Sul 1, à esquerda, e Trilha Norte-Sul 2, à direita).

MAN: Mandaqui, VAN: Vila Andrade, TRE: Tremembé, MOR: Morumbi, CAC: Cachoeirinha, TUC: Tucuruvi, MOE: Moema, PIN: Pinheiros, SAN: Santana, JPA: Jardim Paulista, CON: Consolação, PER: Perdizes, CBE: Campo Belo, JAB: Jabaquara, IBI: Itaim Bibi, SAM: Santo Amaro, SAL: Saúde, BFU: Barra Funda, LIB: Liberdade, VMA: Vila Mariana, CVE: Casa Verde, BRE: Bom Retiro, BVI: Bela Vista, PAR: Pari, JAC: Jaçanã, LIM: Limão, VME: Vila Medeiros, SCE: Santa Cecília, VGU: Vila Guilherme, SE: Sé, CAM: Cambuci, REP: República, BRS: Brás, API: Alto de Pinheiros, LAP: Lapa, FRE: Freguesia do Ó, BEL: Belém, MOO: Mooca. 


\section{CONCLUSÕES}

Dentre a região amostrada, os distritos paulistanos mais arborizados e que apresentam porcentagem de vegetação ideal, prevista pela literatura, são aqueles com maior renda e com maior disparidade social. Os espaços vegetados estão associados às regiões nobres desses distritos, enquanto que as regiões com menor renda apresentam-se com porcentagem de vegetação muito baixa.

Os distritos menos arborizados se localizam mais próximos da região central de São Paulo, possuem perfil comercial, e sofrem mais intensamente as pressões da urbanização. Apresentam diversos problemas urbanos, como elevados níveis de poluição, ilhas de calor, alagamentos, dentre outros, que reduzem a qualidade de vida da população. Dessa forma, o aumento dos espaços vegetados é primordial nesses locais

É importante para a gestão pública conhecer o uso e ocupação do solo urbano, pois a partir dela é possível estabelecer ações de planejamento mais efetivas, que visem aprimorar a qualidade de vida que a cidade oferece à população.

\section{AGRADECIMENTOS}

Agradecemos à Fundação Capes pela concessão de bolsas, à Fundação DigitalGlobe pela doação de imagens de satélite de alta resolução, e ao Centro de Gerenciamento de Emergências pelo fornecimento de dados utilizados neste trabalho.

\section{REFERÊNCIAS}

ATLAS BRASIL. Ranking São Paulo 2010. Disponível em: <http://atlasbrasil.org. br/2013/pt/ranking >. Acesso em 21/05/17.

BARÓ, F. et al. Contribution of ecosystem services to air quality and climate change mitigation policies: The case of urban forests in Barcelona, Spain. Ambio, v. 43, n. 4, p. 466-479, 2014.

BEYER, K. M. M.; KALTENBACH, S.; BOGAR, S.; NIETO, F.; MALECKI, K.KM. Exposure to neighborhood green space and mental health: Evidence from the survey of the health of Wisconsin. International Journal of Environmental Research and Public Health, v. 11, n. 3, p. 3453-3472, 2014. 
COSTA, J. A. Uso de imagens de alta resolução para definição de corredores verdes na cidade de São Paulo. 2010. 114p. Dissertação (Mestrado) - Escola Superior de Agricultura “Luiz de Queiroz, Universidade de São Paulo, Piracicaba, 2010.

DIGITALGLOBE FUNDATION. Disponível em: <http://www.digitalglobefoundation.org/>. Acesso em 17 nov. 2016.

FRANCO. Infraestrutura verde para a resiliência urbana às mudanças climáticas da cidade de São Paulo. Relatório Científico de Progresso (R-1 FAPESP/ANUAL). Processo 15/10597-0. Faculdade de Arquitetura Urbanismo e Design da Universidade de São Paulo, 2016.

IBGE. Instituto Brasileiro de Geografia e Estatística. 2010. Disponível em: <http:// cidades.ibge.gov.br/xtras/perfil.php?codmun=355030>. Acesso em: 20. mar. 2017.

KÖPPEN, W. Climatologia: con un estudio de los climas de la tierra. Fondo de Cultura Econômica. México. 1948. 479p.

LEFF, M. The Sustainable Urban Forest: A Step-by-Step Approach. Davey Institute / USDA Forest Service. 2016. 102p.

LI, H.; CHEN, W.; HE, W. Planning of green space ecological network in urban areas: an example of Nanchang, China. International Journal of Environmental Research and Public Health, v. 12, n. 10, p. 12889-12904, out. 2015.

MAHER, B. A. et al. Impact of roadside tree lines on indoor concentrations of traffic-derived particulate matter. Environmental Science and Technology, v. 47, n. 23, p. 13737-13744, 2013.

MCPHERSON, E. Gregory. Accounting for benefits and costs of urban greenspace. Landscape and Urban Planning, v. 22, n. 1, p. 41-51, 1992.

NOBRE C.A.; YOUNG, A.F.; SALDIVA, P.; MARENGO, J.A.; NOBRE, A.D.; ALVES JR., S.; SILVA, G.M.C.; LOMBARDO, M. Vulnerabilidade das Megacidades Brasileiras às Mudanças Climáticas: Região Metropolitana de São Paulo, Relatório Final. Instituto Nacional de Pesquisas Espaciais-INPE, Sumário executivo, p.32, 2010. 
NOWAK, D. J.; HIRABAYASHI, S.; GREENFIELD, E. Tree and forest effects on air quality and human health in the United States. Environmental Pollution, v. 193, p. 119-129, 2014.

O ESTADO DE S. PAULO. Vila Andrade, o 'novo Morumbi', é o bairro que mais cresce, 2014. Acesso em: 17 jun. 17. Disponível em: <http://sao-paulo.estadao.com.br/ noticias/geral,vila-andrade-o-novo-morumbi-e-o-bairro-que-mais-cresce,1607979>. 